\title{
The efficacy and safety of induction chemotherapy combined with concurrent chemoradiotherapy versus concurrent chemoradiotherapy alone in nasopharyngeal carcinoma patients: a systematic review and meta-analysis
}

\author{
Bi-Cheng Wang ${ }^{1 *}$ (D) Bo-Ya Xiao², Guo-He Lin ${ }^{3}$, Chang Wang ${ }^{4}$ and Quentin Liu ${ }^{5}$
}

\begin{abstract}
Background: Induction chemotherapy (IC) combined with concurrent chemoradiotherapy (CCRT) has been recommended as the first-line therapy for locoregional nasopharyngeal carcinoma (NPC). Due to the different chemotherapeutic drugs used in the IC and CCRT, the results remain controversial.

Methods: PubMed, EMBASE, Web of Science, and Cochrane Library databases were systematically retrieved to search potentially eligible clinical trials up to Sep 11, 2019. Eligible studies were registered and prospective randomized controlled clinical trials.
\end{abstract}

Results: From 526 records, nine articles including seven randomized controlled clinical trials were eligible, with a total of 2311 locoregional advanced NPC patients. IC + CCRT had significantly lower risks of death (3-year hazard ratio [HR]: 0.70, 95\% confidence interval [Cl] 0.55-0.89, $p=0.003$; 5-year HR: 0.77, 95\% Cl 0.62-0.94, $p=0.01$ ), disease progression (3-year HR: $0.67,95 \%$ Cl 0.55-0.80, $p<0.001$; 5-year HR: 0.70, 95\% Cl 0.58-0.83, $p<0.0001$ ), distant metastasis (3-year HR: $0.58,95 \% \mathrm{Cl} 0.45-0.74, p<0.0001 ; 5$-year HR: $0.69,95 \% \mathrm{Cl} 0.55-0.87, p=0.001$ ) and locoregional relapse (3-year HR: 0.69, 95\% Cl 0.50-0.95, $p=0.02$; 5-year HR: 0.66, 95\% Cl 0.51-0.86, $p=0.002$ ) than CCRT. Compared with CCRT, IC + CCRT showed higher relative risks of grade 3 or more neutropenia, thrombocytopenia, nausea, vomiting and hepatotoxicity throughout the course of treatment, and higher relative risks of grade $\geq 3$ thrombocytopenia and vomiting during CCRT.

Conclusion: IC combined with CCRT significantly improved the survival in locoregional advanced NPC patients. Moreover, toxicities were well tolerated during IC and CCRT. Further clinical trials are warranted to confirm the optimal induction chemotherapeutic regimen in the future.

Keywords: Induction chemotherapy, Concurrent chemoradiotherapy, Survival, Nasopharyngeal carcinoma, Metaanalysis

\footnotetext{
* Correspondence: bcsnowell@163.com

'Cancer Center, Union Hospital, Tongji Medical College, Huazhong University of Science and Technology, Wuhan 430022, China

Full list of author information is available at the end of the article
}

C C The Author(s). 2020 Open Access This article is licensed under a Creative Commons Attribution 4.0 International License, which permits use, sharing, adaptation, distribution and reproduction in any medium or format, as long as you give appropriate credit to the original author(s) and the source, provide a link to the Creative Commons licence, and indicate if changes were made. The images or other third party material in this article are included in the article's Creative Commons licence, unless indicated otherwise in a credit line to the material. If material is not included in the article's Creative Commons licence and your intended use is not permitted by statutory regulation or exceeds the permitted use, you will need to obtain permission directly from the copyright holder. To view a copy of this licence, visit http://creativecommons.org/licenses/by/4.0/. The Creative Commons Public Domain Dedication waiver (http://creativecommons.org/publicdomain/zero/1.0/) applies to the data made available in this article, unless otherwise stated in a credit line to the data. 


\section{Highlights}

1. IC combined with CCRT significantly improved the survival outcomes of patients with locoregional advanced NPC.

2. IC combined with CCRT showed higher relative risks of grade 3 or more neutropenia, thrombocytopenia, nausea, vomiting and hepatotoxicity throughout the course of treatment, and higher relative risks of grade 3 or more thrombocytopenia and vomiting during CCRT.

\section{Background}

Nasopharyngeal carcinoma (NPC) is one of head and neck tumors with an unbalanced endemic distribution and a high prevalence in Southeast Asia, Southeast China, and North Africa [1]. More than two decades ago, locoregionally advanced NPC had an unfavorable prognosis. Since the administration of concurrent chemoradiotherapy (CCRT), the survival outcomes have been significantly improved $[2,3]$.

However, there are still over $20 \%$ of patients with locoregionally advanced NPC living for less than 5 years [3]. In the European Society for Medical Oncology (ESMO) clinical practice guideline, CCRT is suggested to treat locoregionally advanced NPC (category 1A), while induction chemotherapy (IC) combined with CCRT is recommended to stage IV NPC patients (category 2B) [4]. Nevertheless, this guideline has not been updated since 2012.

In the National Comprehensive Cancer Network $(\mathrm{NCCN})$ clinical practice guideline for patients with locoregionally advanced NPC, the preferred recommendation is participating in clinical trials, while the category $2 \mathrm{~A}$ and $2 \mathrm{~B}$ recommendations are, respectively, IC followed by CCRT and CCRT alone [5].

In the past decade, considerable studies on IC for NPC have been carried out. Among these clinical trials, different chemotherapeutic drugs and different doses or cycles of the IC were administered. However, owing to multiple clinical trials showing different results, adding IC to CCRT remains controversial.

Accordingly, in this systematic review and metaanalysis, we compared the IC plus CCRT with CCRT alone in NPC patients to analyze the 3-year/5-year survival outcomes and grade $\geq 3$ toxicities in the registered and prospective clinical studies.

\section{Methods}

This analysis was conducted according to the Preferred Reporting Items for Systematic Reviews and Metaanalyses guideline (PRISMA) [6].

\section{Search strategy}

A systematic literature search was performed in PubMed, EMBASE, Web of Science, and Cochrane Library databases to identify all relevant records up to Sep 11, 2019. Search terms included: "induction chemotherapy", "concurrent chemoradiotherapy", "nasopharyngeal carcinoma", and "randomized controlled trial or randomized clinical trial or clinical trial or trial". The references of relevant articles were manually searched for more clinical studies. The search records were uploaded into EndNote software (http://endnote.com/) for further review.

\section{Selection criteria}

All of the eligible clinical trials should meet the following inclusion criteria: (1) prospective studies in previously untreated patients with NPC, (2) all eligible studies were registered clinical trials and provided the registered numbers, (3) only randomized controlled clinical studies were eligible, (4) in randomized controlled studies, the experiment group was treated with IC combined with CCRT, and the control group was treated with CCRT alone, (5) neoadjuvant chemotherapy described in the articles was deemed as induction chemotherapy, (6) IC or CCRT combined with target therapy was excluded, (7) because of the absence of complete efficacy and safety data, conference abstracts were excluded, (8) studies were published in English. Any disagreements were resolved by discussion.

\section{Data extraction and quality assessment}

The primary outcome was overall survival (OS), failurefree survival (FFS), distant metastasis-free survival (DMFS) and locoregional relapse-free survival (LRFS), and the second outcome was toxicity. FFS was defined as the date of randomization to documented disease progression (the date of locoregional/distant failure or death from any cause, whichever occurred first). Two authors (BW and BX) independently extracted information from the full texts and supplementary materials. Any discrepancies were resolved by consensus. The following details were extracted from each eligible clinical trial: first author, publication year, inclusion period, registered number, study design, number of patients, mean age, median follow-up, therapeutic regimens, OS, FFS, DMFS, LRFS, survival rate, and adverse events. The Jadad scoring scale was used to evaluate the methodological quality of each eligible trial by two authors (BW and BX) [7].

\section{Statistical analysis}

Survival outcomes (OS, FFS, DMFS and LRFS) from randomized controlled studies were assessed by hazard ratio (HR) with 95\% confidence interval (CI) using Cochrane Collaboration's Information Management System 
(RevMan) software (version 5.3). Toxicities were calculated as risk ratios (RRs) and 95\% CIs. The chi-squared $\left(\mathrm{X}^{2}\right)$ tests and $I^{2}$ statistic percentages were used to test and quantify the heterogeneity. A fixed-effects model (Mantel-Haenszel method) was adopted in the calculations if $I^{2} \leq 50 \%$, otherwise, a random-effect model was applied. When $p<0.05$, the differences were considered statistically significant.

\section{Results}

\section{Eligible studies and characteristics}

Our search of the PubMed, EMBASE, Web of Science, and Cochrane Library databases identified 524 relevant publications. Two additional records were identified through reference lists. 167 duplicated records were removed. After screening the titles and abstracts, 195 records were excluded. After eligibility assessment, a total of nine studies were selected for inclusion in the systematic review, comprising seven randomized controlled studies (Fig. 1) [8-16]. Table 1 showed the basic characteristics of the eligible clinical trials. Table 2 displayed the details of therapeutic regimens and rates of OS, FFS, objective response, and grade $\geq 3$ toxicities in the selected studies.

Across the eligible studies, Zhang et al showed the highest rates of 3-year survival outcomes for patients treated with IC plus CCRT (OS: $94.6 \%$ versus $90.3 \%$ in CCRT group; FFS: $85.3 \%$ versus $76.5 \%$ in CCRT group). In Frikha's study, the IC + CCRT group had the greatest improvements in 3-year survival rates compared with CCRT group (OS: $86.3 \%$ versus $68.9 \%$; FFS: $73.9 \%$ versus $57.2 \%)$. In the setting of 5-year survival data, Yang et al exhibited that IC plus CCRT significantly increased the efficacy against CCRT alone (OS: $80.8 \%$ versus $76.8 \%$, $p=0.04$; FFS: $73.4 \%$ versus $63.1 \%, p=0.007)$. However, IC followed by CCRT had similar objective response rates (ORRs) compared to CCRT (e.g. Fountzilas' study: $83 \%$ versus $85 \%, p=0.82$; Cao's study: $98.7 \%$ versus $99.2 \%, p>0.05)$. For grade $\geq 3$ adverse events, the rates in the IC+CCRT group ranged from 52.0 to $75.7 \%$, which is significantly increased in comparison with the CCRT group (ranged from 37.0 to $55.7 \%$ ).

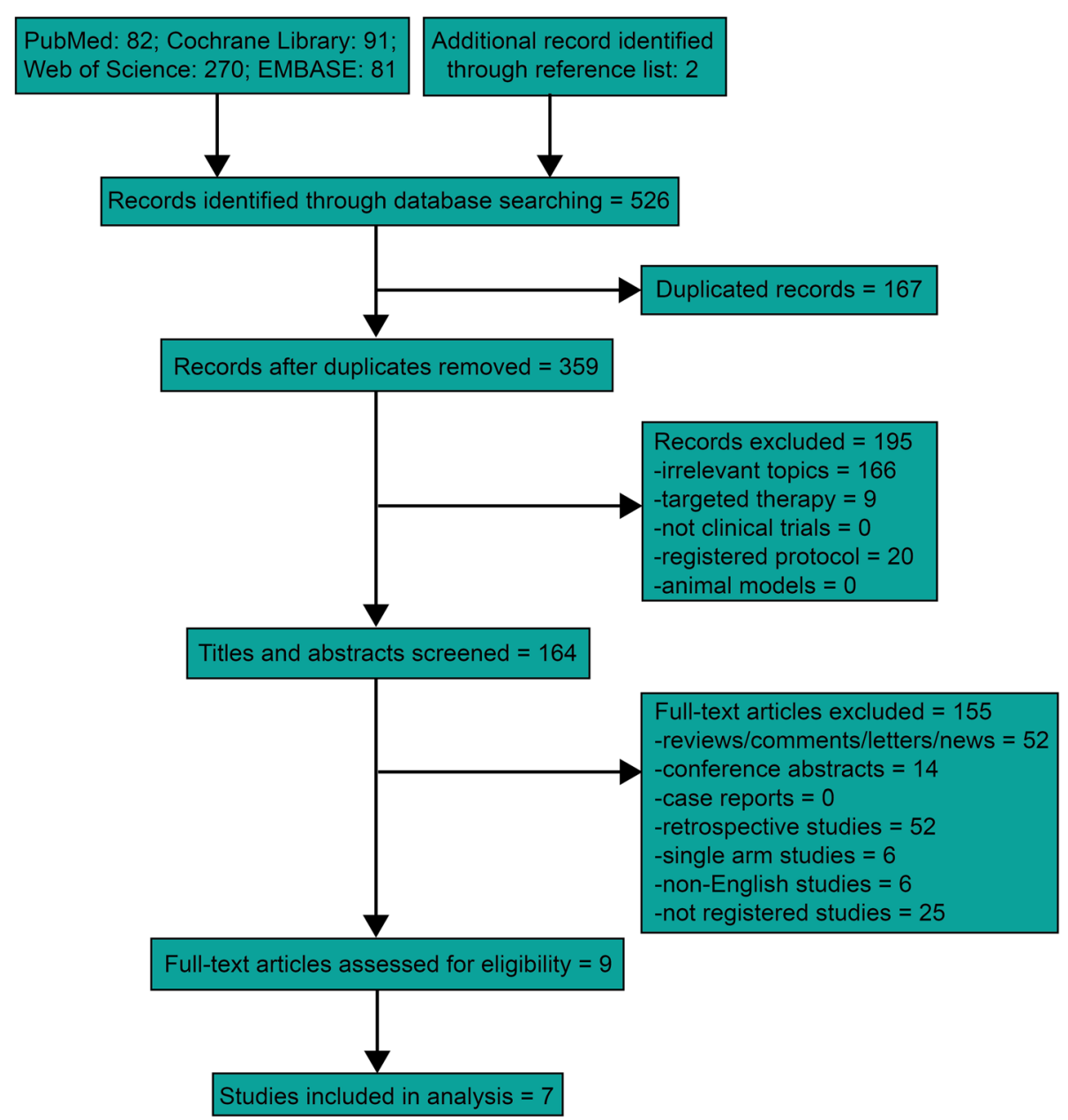

Fig. 1 Flow chart of the selection process 


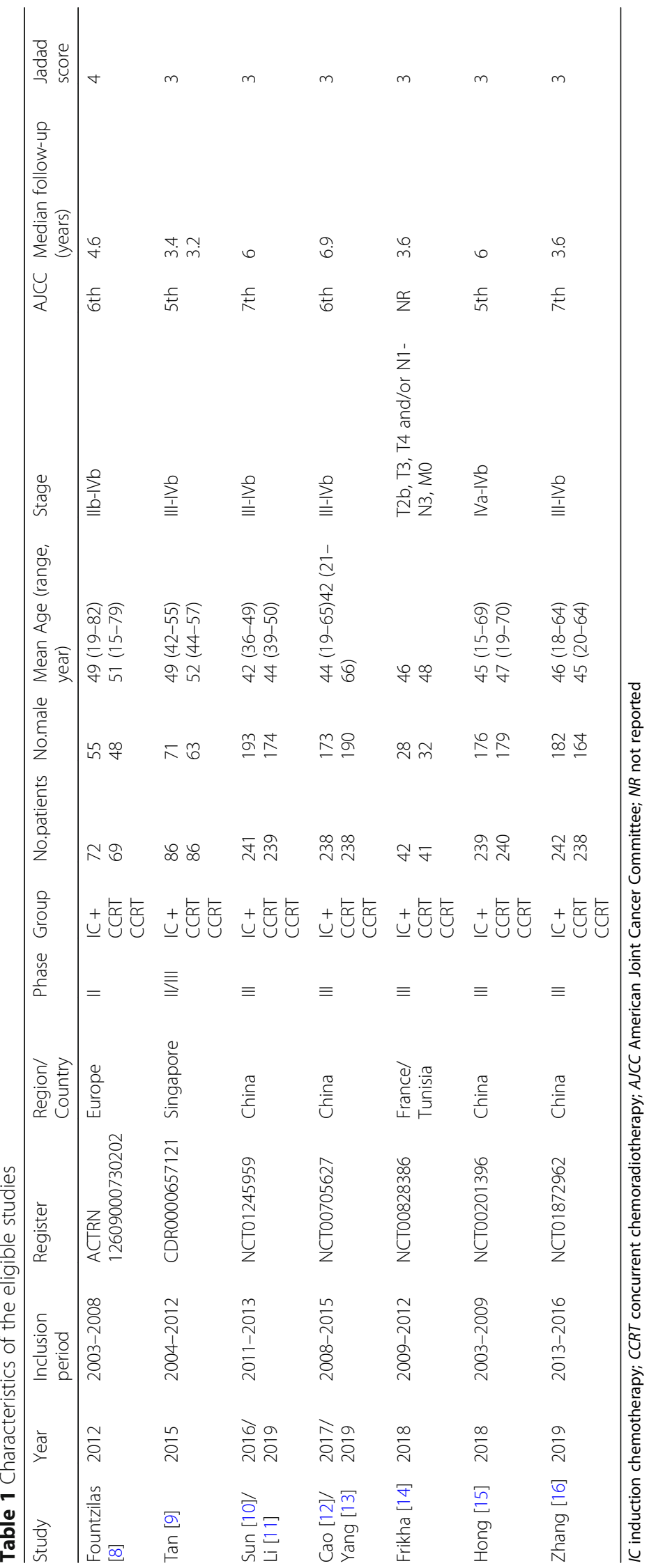




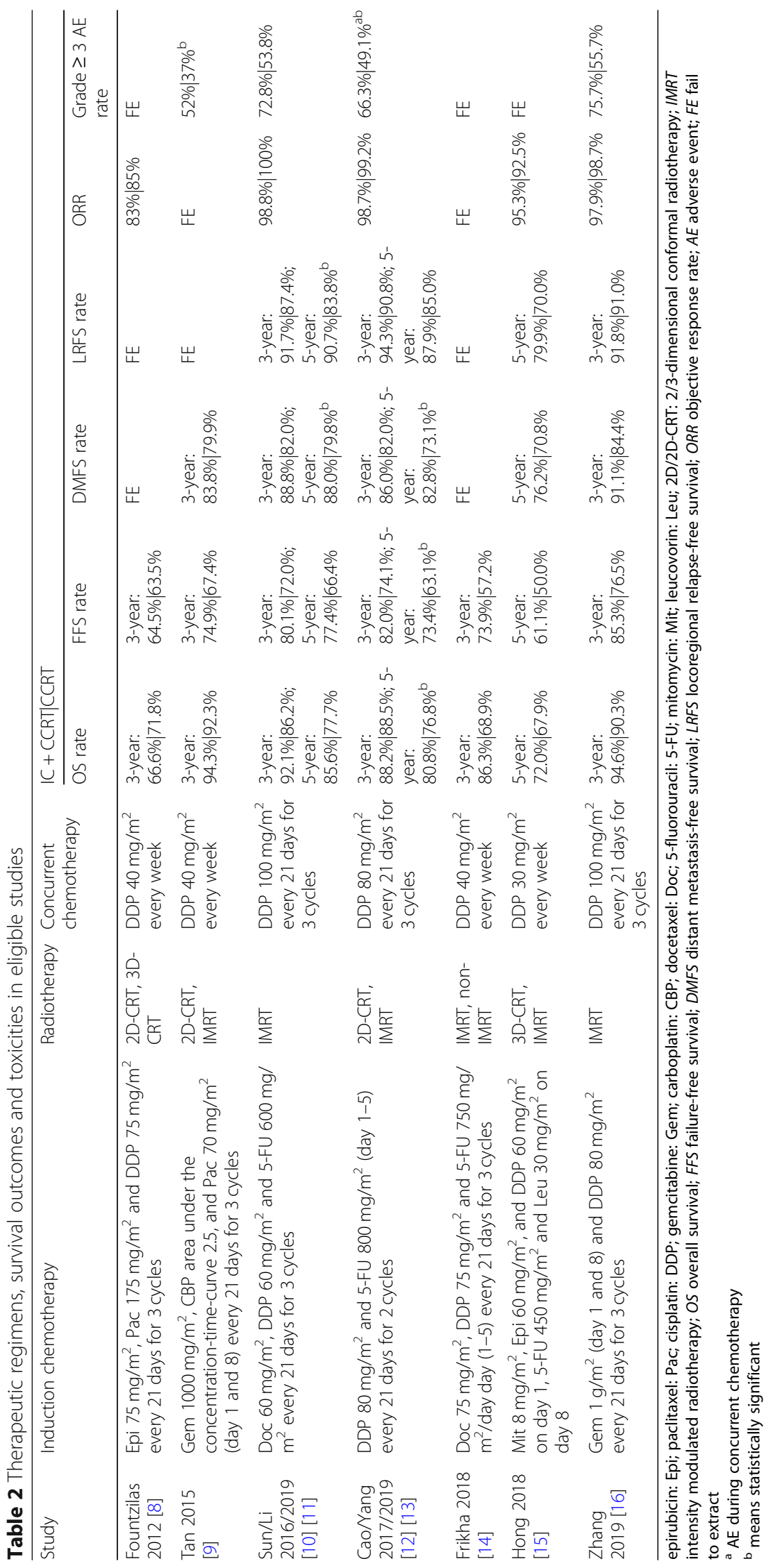




\section{Overall survival (OS)}

3-year OS data were available from six randomized controlled trials with 1832 patients (IC + CCRT group: 921 patients; CCRT group: 911 patients). Forest plots showed patients obtained greater OS benefit from IC + CCRT compared with CCRT alone (HR: 0.70, 95\% CI: 0.55-0.89, $p=0.003$; H: $I^{2}=33 \%, p=0.19$ ) (Fig. 2a).

5 -year OS data were available from three randomized controlled trials with 1435 patients (IC + CCRT group: 718 patients; CCRT group: 717 patients). Pooled results indicated that $\mathrm{IC}+\mathrm{CCRT}$ led to significantly superior OS than CCRT (HR: 0.77, 95\% CI: 0.62-0.94, $p=0.01$; $\mathrm{H}: I^{2}=12 \%, p=0.32$ ) (Fig. 2b).

\section{Failure-free survival (FFS)}

3-year FFS data were extracted from six randomized controlled studies involving 1832 patients (IC + CCRT group: 921 patients; CCRT group: 911 patients). IC + CCRT appeared to show better FFS than CCRT (HR: 0.67, 95\% CI: 0.55-0.80, $p<0.0001 ; \mathrm{H}: I^{2}=34 \%, p=0.18$ )

(Fig. 3a).

5-year FFS data were extracted from three randomized controlled studies involving 1435 patients (IC + CCRT group: 718 patients; CCRT group: 717 patients). IC + CCRT exhibited significant FFS superiority compared with CCRT (HR: 0.70, 95\% CI: 0.58-0.83, $p<0.0001$; H: $I^{2}=0 \%, p=0.84$ ) (Fig. 3b).

\section{Distant metastasis-free survival (DMFS)}

The data of 3-year DMFS were available from five randomized controlled studies with 1691 patients (IC + CCRT group: 849 patients; CCRT group: 842 patients).
The DMFS value was significantly prolonged for patients treated with IC + CCRT compared with CCRT (HR: 0.58, 95\% CI: $0.45-0.74, p<0.0001 ; \mathrm{H}: I^{2}=0 \%, p=0.72$ )

(Fig. 4a).

5-year DMFS data were available from three randomized controlled studies with 1435 patients (IC+ CCRT group: 718 patients; CCRT group: 717 patients). A significantly lower risk of distant metastasis was shown in the IC + CCRT group versus the CCRT group (HR: 0.69, 95\% CI: 0.55-0.87, $p=0.001 ; \mathrm{H}: I^{2}=$ $0 \%, p=0.42$ ) (Fig. 4b).

\section{Locoregional relapse-free survival (LRFS)}

3-year LRFS data were collected from four randomized controlled studies involving 1519 patients (IC + CCRT group: 763 patients; CCRT group: 756 patients). Consistent with the results for DMFS, patients receiving IC + CCRT appeared to exhibit better LRFS than those receiving CCRT (HR: 0.69, 95\% CI: 0.50-0.95, $p=0.02$; H: $I^{2}=0 \%, p=0.70$ ) (Fig. 5a).

5 -year LRFS data were collected from three randomized controlled studies involving 1435 patients (IC + CCRT group: 718 patients; CCRT group: 717 patients). The IC + CCRT group showed a statistically significant lower risk of locoregional relapse than the CCRT group (HR: 0.66, 95\% CI: 0.51-0.86, $p=0.002$; $\mathrm{H}: I^{2}=0 \%, p=$ 0.80) (Fig. 5b).

\section{Grade $\geq 3$ toxicities}

For grade 3 or more adverse events during the IC and CCRT, two randomized controlled trails compared the IC plus CCRT group against the CCRT group [10, 11,

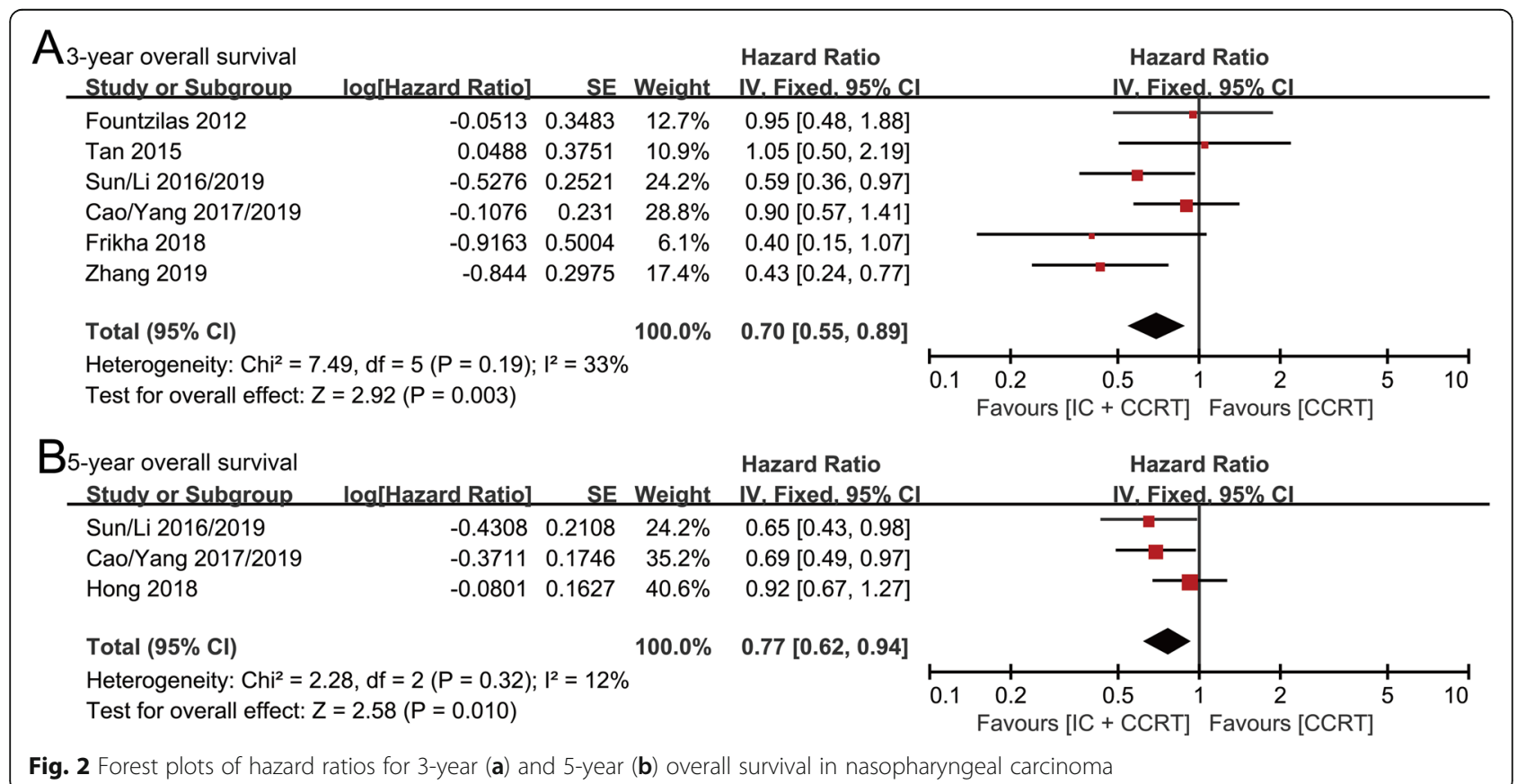




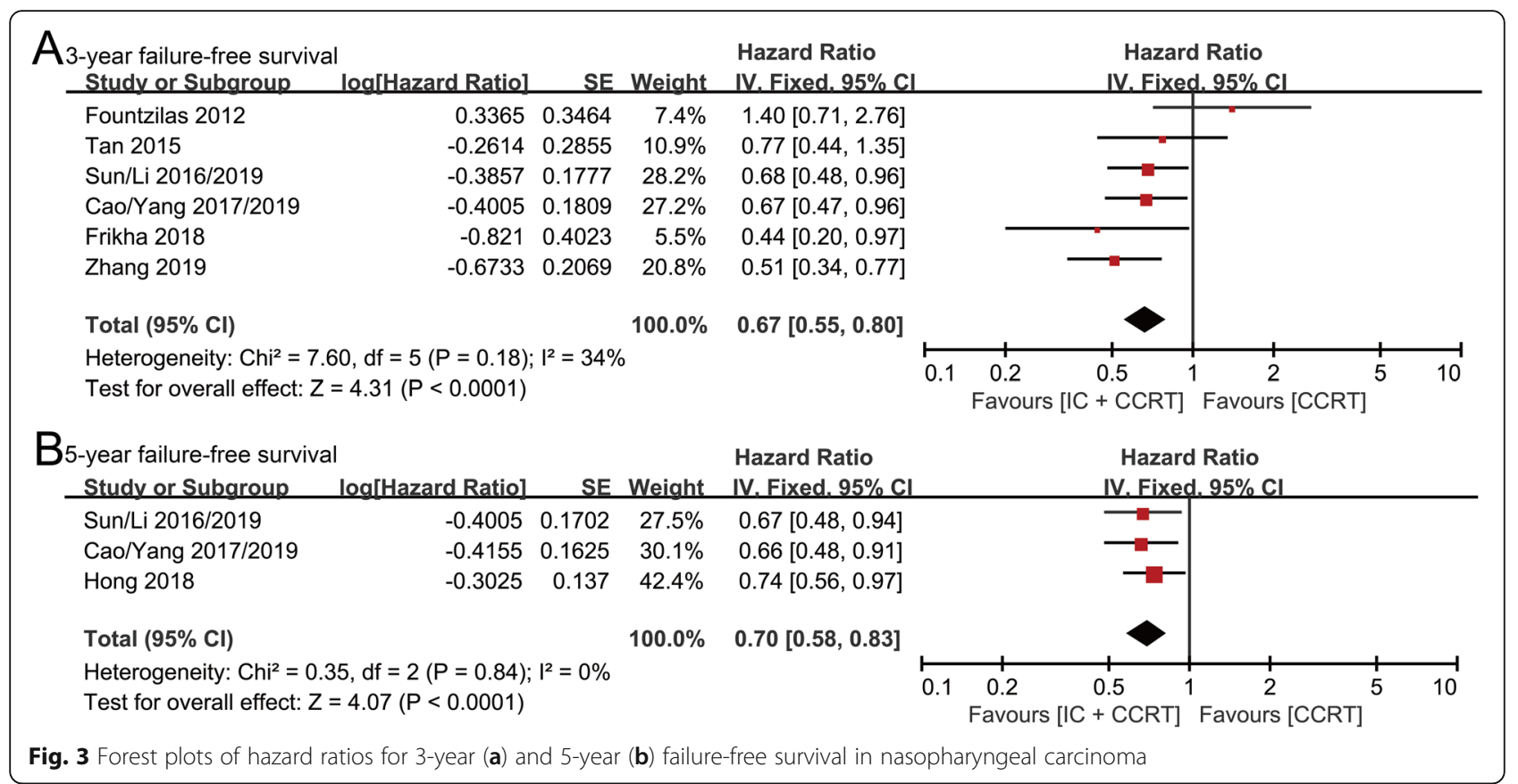

16]. In hematological toxicities, there were no significant differences in leukopenia (risk ratio [RR]: 1.77, 95\% CI: $0.98-3.19, p=0.06$ ) and anemia (RR: 2.97, 95\% CI: 0.2044.40, $p=0.43$ ) between IC + CCRT group and CCRT group. However, the IC + CCRT group showed significantly high risks of neutropenia (RR: 3.93 , 95\% CI: $1.78-$ 8.68, $p=0.0007$ ) and thrombocytopenia (RR: 6.55, 95\% CI: $2.58-16.63, p<0.0001)$ than the CCRT group (Fig. 6a-d). In non-hematological toxicities, patients treated with $\mathrm{IC}+\mathrm{CCRT}$ showed significantly higher risks of nausea (RR: $1.43,95 \% \mathrm{CI}: 1.09-1.87, p=0.01$ ), vomiting (RR: 1.40, 95\% CI: $1.08-1.82, p=0.01$ ) and hepatotoxicity (RR: $5.37,95 \% \mathrm{CI}: 1.40-20.58, p=0.01$ ) rather than stomatitis (RR: $1.04,95 \% \mathrm{CI}: 0.87-1.24, p=0.68$ ) and dermatitis (RR: 0.73 , 95\% CI: $0.37-1.44, p=0.37$ ) in comparison with patients treated with CCRT (Fig. 6e-i).

For grade $\geq 3$ adverse events during the CCRT, in hematological toxicities, patients in IC + CCRT group showed significantly higher risks of thrombocytopenia (RR: 11.67, 95\% CI: 2.46-55.34, $p=0.002$ ) and anemia

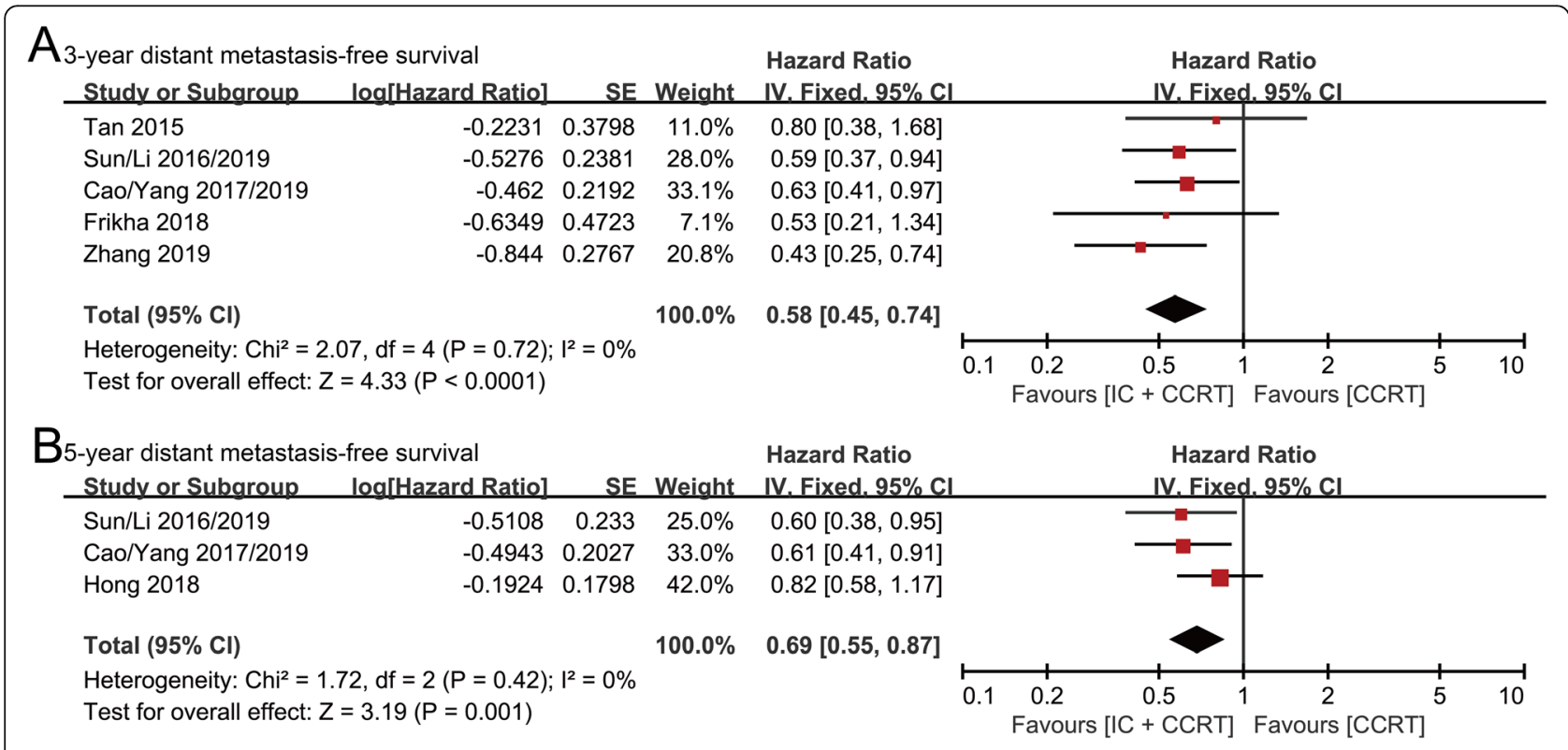

Fig. 4 Forest plots of hazard ratios for 3-year (a) and 5-year (b) distant metastasis-free survival in nasopharyngeal carcinoma 


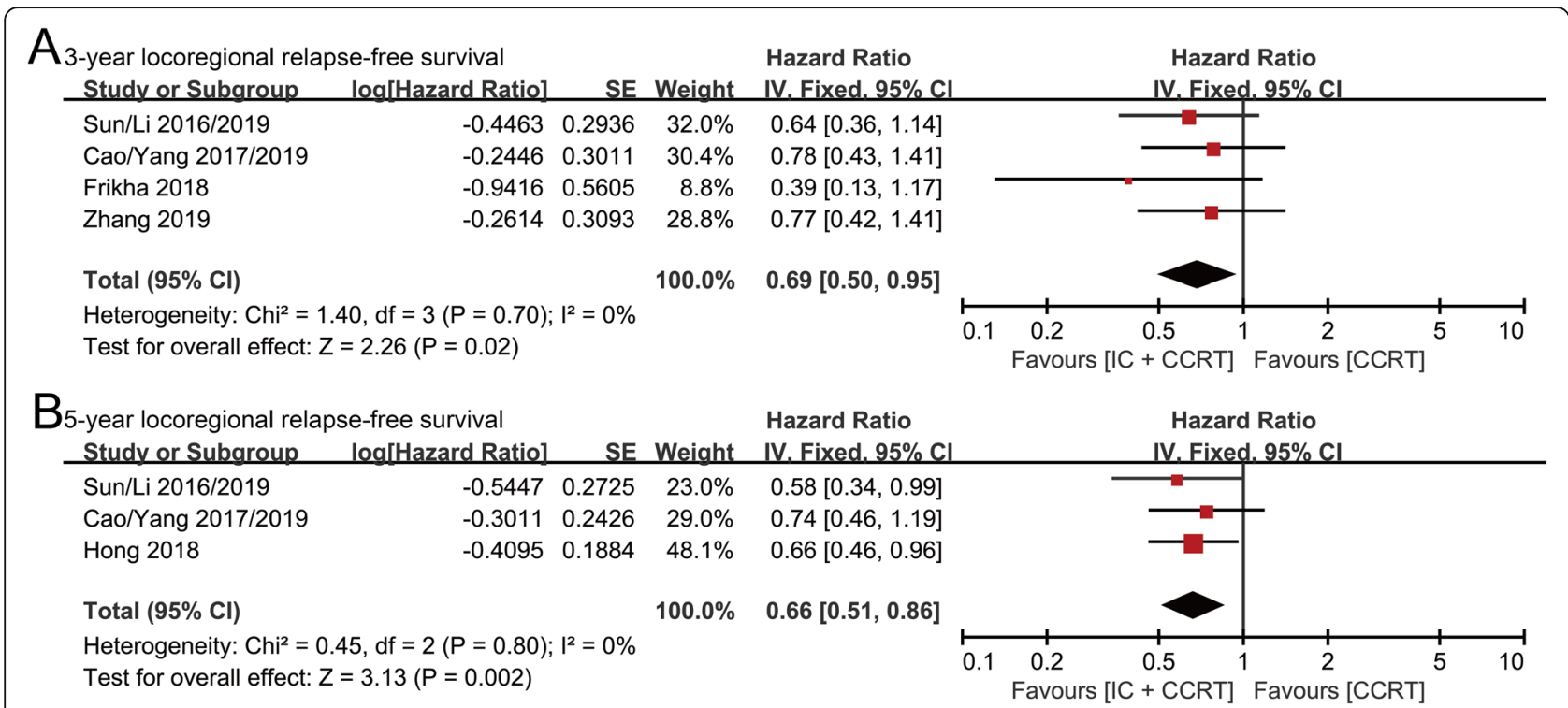

Fig. 5 Forest plots of hazard ratios for 3-year (a) and 5-year (b) locoregional relapse-free survival in nasopharyngeal carcinoma

(RR: 3.81, 95\% CI: 2.11-6.87, $p<0.00001$ ) than patients in CCRT group. There were no significant differences in leukopenia (RR: $1.41,95 \%$ CI: $1.01-1.96, p=0.05$ ) and neutropenia (RR: $1.26,95 \%$ CI: $0.68-2.34, p=0.47$ ) between IC + CCRT group and CCRT group (Fig. 7a-d). In non-hematological toxicities, patients treated with IC + CCRT showed a significantly higher risk of vomiting (RR: $0.62,95 \%$ CI: $0.40-0.94, p=0.03$ ) rather than fatigue (RR: $1.52,95 \% \mathrm{CI}: 0.06-37.10, p=0.80$ ), nausea (RR: $1.44,95 \%$ CI: $0.63-3.33, p=0.39$ ), stomatitis (mucositis) (RR: $0.88,95 \%$ CI: $0.73-1.05, p=0.16$ ) and dermatitis (RR: 1.34, 95\% CI: 0.20-9.04, $p=0.76$ ) in comparison with patients treated with CCRT (Fig. 7e-i).

\section{Publication bias}

Using the Jadad scoring scale, all enrolled trials were identified as high quality (a score of $\geq 3$ ).

\section{Discussion}

In this meta-analysis, all survival data were significantly better in NPC patients treated with IC combined with CCRT than that in patients treated with CCRT alone.

We conducted this meta-analysis to estimate the efficacy and safety of IC combined with CCRT in NPC patients. There were several early meta-analyses indicating the benefits of IC in treating patients with locoregionally advanced NPC. However, most of the studies were published before 2018 (Table 3) [17-21]. Song synthesized only four randomized clinical studies and demonstrated that IC followed CCRT performed significant treatment effects in DMFS and progression-free survival (PFS) rather than OS and LRFS [18]. In a network meta-analysis conducted by Chen, the results showed that IC plus
CCRT had a higher risk of locoregional recurrence than CCRT and found no significant improvement in OS [17]. Tan analyzed six randomized controlled studies and five observation studies and displayed significant improvement in OS and PFS without the analyses of DMFS and LRFS [21]. Moreover, the inclusion of retrospective studies might increase the bias of the analysis. Although Ouyang's pairwise meta-analysis confirmed the benefit in OS, PFS, DMFS and LRFS in NPC, patients in four of 10 included studies were treated with radiotherapy alone without concurrent chemotherapy [19]. Thus, we considered that the previous meta-analysis might not fully demonstrate the efficacy of IC + CCRT in the treatment of NPC compared with CCRT. In order to minimize the bias, we selected prospective and clinical registered randomized controlled clinical trials as the eligible studies.

Over $70 \%$ of newly diagnosed NPC patients were classified as locoregionally advanced diseases [22]. Although IMRT combined with concurrent chemotherapy improved the locoregional control, long-term survival outcomes were poor. Distant recurrence might be a major reason for the treatment failure in long-term survived patients [23-25]. The efficacy of IC in the IC + CCRT group was due to the lower incidence of distant metastatic recurrence than that in the CCRT group. In Li's study, patients from the IC plus CCRT group showed significantly better 5 -year DMFS $88 \%$ versus $79.8 \%$; $p=$ 0.030 ) [11], while the corresponding figures reported by Yang et al. were $82.8 \%$ versus $73.1 \%, p=0.014$ [13].

Patients could achieve better response rates and have longer survival outcomes with the administration of a more effective chemotherapeutic regimen. That is why the efficacy of IC plus CCRT in NPC is controversial 


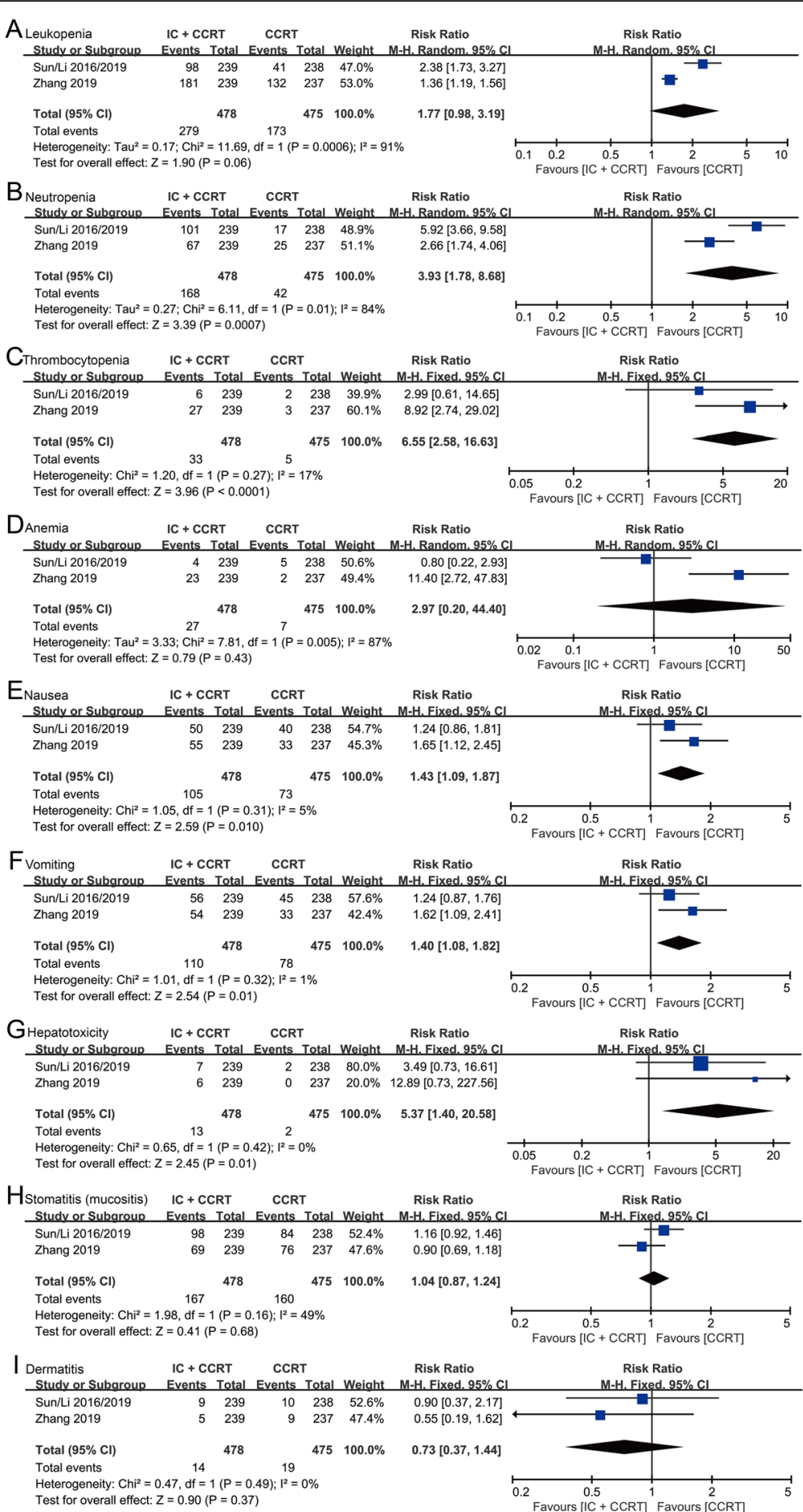

Fig. 6 Forest plots of risk ratios for cumulative grade $\geq 3$ hematological and non-hematological toxicities during overall treatment. (a-d) Cumulative grade $\geq 3$ hematological toxicities (leukopenia (a), neutropenia (b), thrombocytopenia (c), and anemia (d)) during overall treatment. (e-i) cumulative grade $\geq 3$ non-hematological toxicities (nausea (e), vomiting (f), hepatotoxicity (g), stomatitis (mucositis) (h), and dermatitis (i) during overall treatment

[26-38]. A phase II randomized clinical study compared induction docetaxel + cisplatin plus CCRT against CCRT alone, indicating IC significantly increased 3-year OS, and positive effects on PFS and DMFS [39].
However, another phase II clinical study showed that IC of cisplatin combined with paclitaxel and epirubicin followed with CCRT did not significantly improve OS and PFS compared with CCRT alone in NPC [8]. 


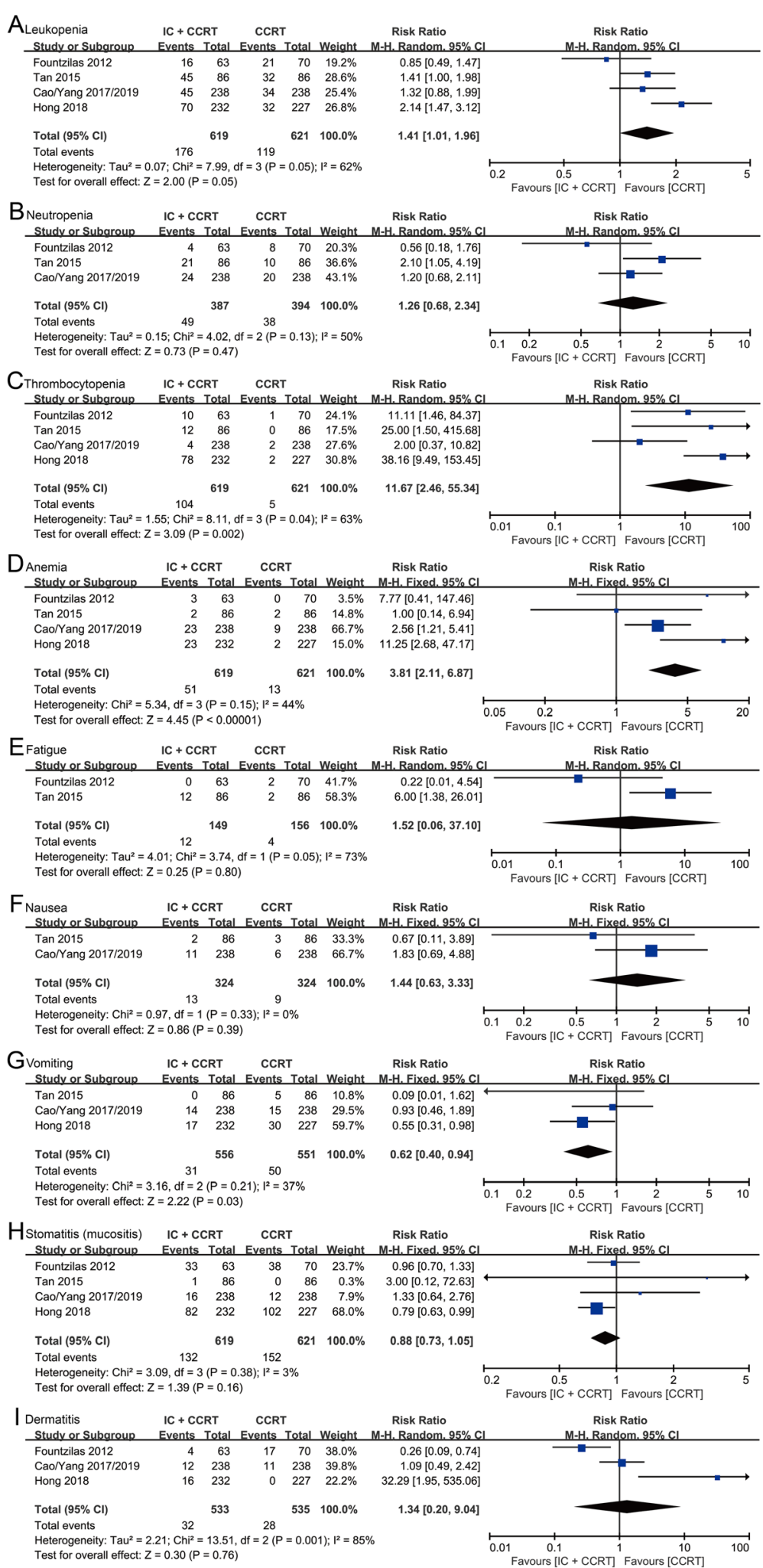

Fig. 7 Forest plots of risk ratios for grade $\geq 3$ hematological and non-hematological toxicities during concurrent chemoradiotherapy. (a-d) Grade $\geq 3$ hematological toxicities (leukopenia (a), neutropenia $(\mathbf{b})$, thrombocytopenia (c), and anemia (d)) during concurrent chemoradiotherapy. (e-i) Grade $\geq 3$ non-hematological toxicities (fatigue (e), nausea (f), vomiting (g), stomatitis (mucositis) (h), and dermatitis (i) during concurrent chemoradiotherapy 
Table 3 Summary of the cited meta-analyses and this study

\begin{tabular}{|c|c|c|c|c|c|}
\hline Survival outcomes $^{a}$ & Total Patients & OS & FFS & DMFS & LRFS \\
\hline Chen 2015 [17] & 206 & $\begin{array}{l}\text { HR 0.70, } \\
95 \% \text { Cl } 0.39-1.26\end{array}$ & $\mathrm{FE}$ & $\begin{array}{l}\text { RR 0.51, } \\
95 \% \text { Cl } 0.28-0.95\end{array}$ & $\begin{array}{l}\text { RR 1.65, } \\
95 \% \mathrm{Cl} 0.95-2.86\end{array}$ \\
\hline Song 2015 [18] & 798 & $\begin{array}{l}\text { HR 0.52, } \\
95 \% \text { Cl } 0.21-1.29\end{array}$ & $\begin{array}{l}\text { HR 0.66, } \\
95 \% \text { Cl } 0.49-0.90\end{array}$ & $\begin{array}{l}\text { HR 0.60, } \\
95 \% \text { Cl } 0.39-0.98\end{array}$ & $\begin{array}{l}\text { HR 0.66, } \\
95 \% \mathrm{Cl} 0.16-2.65\end{array}$ \\
\hline Ouyang 2019 [19] & 1418 & $\mathrm{FE}$ & $\mathrm{FE}$ & $\mathrm{FE}$ & $\mathrm{FE}$ \\
\hline Chen 2018 [20] & 1193 & $\begin{array}{l}\text { HR 0.75, } \\
95 \% \text { Cl } 0.57-0.99\end{array}$ & $\begin{array}{l}\text { HR 0.70, } \\
95 \% \text { Cl } 0.56-0.86\end{array}$ & $\begin{array}{l}\text { HR 0.68, } \\
95 \% \text { Cl } 0.51-0.90\end{array}$ & $\begin{array}{l}\text { HR 0.70, } \\
95 \% \mathrm{Cl} 0.48-1.01\end{array}$ \\
\hline Tan 2018 [21] & 2802 & $\begin{array}{l}\text { HR 0.77, } \\
95 \% \mathrm{Cl} 0.60-0.98\end{array}$ & $\begin{array}{l}\text { HR 0.69, } \\
95 \% \mathrm{Cl} 0.57-0.84\end{array}$ & $\begin{array}{l}\text { HR 0.63, } \\
95 \% \text { Cl } 0.47-0.83\end{array}$ & $\begin{array}{l}\text { HR 0.66, } \\
95 \% \text { Cl } 0.45-0.96\end{array}$ \\
\hline Wang & 2311 & $\begin{array}{l}\text { 3-year: HR 0.70, } \\
\text { 95\% Cl 0.55-0.89; } \\
\text { 5-year: HR 0.77, } \\
\text { 95\% Cl 0.62-0.94 }\end{array}$ & $\begin{array}{l}\text { 3-year: HR 0.67, } \\
\text { 95\% CI 0.55-0.80; } \\
\text { 5-year: HR 0.70, } \\
95 \% \text { Cl 0.58-0.83 }\end{array}$ & $\begin{array}{l}\text { 3-year: HR 0.58, } \\
\text { 95\% CI 0.45-0.74; } \\
\text { 5-year: HR 0.69, } \\
95 \% \text { Cl 0.55-0.87 }\end{array}$ & $\begin{array}{l}\text { 3-year: HR 0.69, } \\
95 \% \text { Cl 0.50-0.95; } \\
\text { 5-year: HR 0.66, } \\
95 \% \text { Cl 0.51-0.86 }\end{array}$ \\
\hline
\end{tabular}

OS overall survival; FFS failure-free survival; DMFS distant metastasis-free survival; LRFS locoregional relapse-free survival; $H R$ hazard ratio; $95 \%$ Cl 95\% confidence interval; $F E$ fail to extract

a data of randomized clinical trials

Moreover, a randomized phase II-III study reported induction gemcitabine, carboplatin, and paclitaxel combined with CCRT had no significant differences in OS, disease-free survival (DFS) and DMFS compared with CCRT alone in patients with locoregionally advanced NPC [9]. A previously prospective clinical study proved that gemcitabine combined with cisplatin might be better than fluorouracil plus cisplatin in the first-line treatment of recurrence/metastatic NPC [40]. A retrospective study showed no significant difference in survival outcomes between induction cisplatin plus gemcitabine and cisplatin in combination with fluorouracil and docetaxel for the treatment of locoregionally advanced NPC [41]. Several ongoing clinical studies might be leading to evaluate the benefit and risk of different induction chemotherapeutic regimens in patients with locoregionally advanced NPC. For instance, NCT03604965, NCT035 03136, and NCT02512315. The verification of the value of these treatment strategies is awaited.

Grade $\geq 3$ adverse events were more frequent in the IC + CCRT group. During IC + CCRT, the most prominent grade $\geq 3$ adverse events were neutropenia, thrombocytopenia, nausea, vomiting and hepatotoxicity. During CCRT, the most prominent grade 3 or more adverse events were thrombocytopenia, anemia and vomiting. However, these toxicities were uncomplicated, tolerated and manageable. We observed that there were no significant differences in radiotherapy related toxicities, comprising stomatitis (mucositis) and dermatitis, between the two groups. For late toxicities, Li et al. reported that the incidence of grade $\geq 3$ late adverse events was $8.8 \%$ in the IC followed by CCRT group and $9.2 \%$ in the CCRT group [11]. Yang's study also showed similar rates of late toxicities between IC + CCRT and CCRT alone group and auditory toxicities were the most common late adverse events [13].
There are several limitations in this analysis. First, different regimens and cycles of IC and CCRT might influence the survival outcomes. Second, two/threedimensional conformal radiotherapy (2D/3D-CRT) and intensity modulated radiotherapy (IMRT) were included in the studies. Although the advent of IMRT had been demonstrated to promote a higher local tumor control rate [23], several studies had shown no significant advantage between 2D-CRT and IMRT in DMFS [24]. Third, late adverse events data were limited for further analyses. Fourth, as the EBV is an important prognostic factor, in this meta-analysis, there is no important biomarker data to suggest that which group of patients based on EBV DNA level has benefited from IC plus CCRT as compared to CCRT alone. Li's trial is the only study in this meta-analysis that performed post-hoc subgroup analysis and demonstrated that patients with EBV $\geq 6000$ copies/ml had FFS benefit when received IC followed by CCRT as compared to CCRT [11].

\section{Conclusion}

This systematic review and meta-analysis demonstrated that, compared with CCRT alone in patients with locoregionally advanced NPC, the addition of IC to CCRT achieved favorable survival rates, and could significantly improve survival outcomes, including OS, FFS, DMFS and LRFS. As the majority of eligible studies have taken place in endemic areas, the results might not be entirely applicable to patients in non-endemic regions (e.g. EBVpatients). Additionally, it should be further explored the best selection of patient subgroups who will get the most benefit from IC plus CCRT as well as the selection of the most effective regimens for induction chemotherapy.

\section{Abbreviations}

IC: Induction chemotherapy; CCRT: Concurrent chemoradiotherapy; NPC: Nasopharyngeal carcinoma; ESMO: European Society for Medical 
Oncology; NCCN: National Comprehensive Cancer Network; PRISMA: Preferred Reporting Items for Systematic Reviews and Meta-analyses; OS: Overall survival; FFS: Failure-free survival; DMFS: Distant metastasis-free survival; LRFS: Locoregional relapse-free survival; PFS: Progression-free survival; DFS: Disease-free survival; HR: Hazard ratio; Cl: Confidence interval; RR: Risk ratio; 2D/3D-CRT: Two/three-dimensional conformal radiotherapy; IMRT: Intensity modulated radiotherapy; ORR: Objective response rate; AE: Adverse event; FE: Fail to extract

\section{Acknowledgements}

We thank the members in the Bi-Cheng Wang's workgroup for helping to improve the grammar and spelling.

\section{Authors' contributions}

Study design: BW, BX, and GL; Data extraction: BW, BX, and GL; Data analysis: BW, BX, and GL; Manuscript writing: BW, CW, and QL; Manuscript edition: BW, CW, and QL. All authors have read and approved the manuscript.

\section{Funding}

This study was supported by the Independent Innovation Foundation of Wuhan Union Hospital (Grant number: 2019-109 to Bi-Cheng Wang) and the Provincial Natural Science Research Project of Anhui Colleges (KJ2017A200 to Guo-He Lin).

\section{Availability of data and materials}

All the published articles and data were available online.

\section{Ethics approval and consent to participate}

Not applicable.

\section{Consent for publication}

Not applicable.

\section{Competing interests}

None.

\section{Author details}

${ }^{1}$ Cancer Center, Union Hospital, Tongji Medical College, Huazhong University of Science and Technology, Wuhan 430022, China. ${ }^{2}$ Eastern Hepatobiliary Surgery Hospital, Second Military Medical University, Shanghai 200438, People's Republic of China. ${ }^{3}$ Department of Oncology, the Second Affiliated Hospital of Anhui Medical University, Hefei 230601, China. ${ }^{4}$ Institute of Anatomy, University of Bern, $\mathrm{CH}-3012$ Bern, Switzerland. ${ }^{5}$ State Key Laboratory of Oncology in South China, Collaborative Innovation Center for Cancer Medicine, Cancer Center, Sun Yat-sen University, Guangzhou 510060, China.

Received: 10 December 2019 Accepted: 28 April 2020

Published online: 06 May 2020

\section{References}

1. Bray F, Ferlay J, Soerjomataram I, Siegel RL, Torre LA, Jemal A. Global cancer statistics 2018: GLOBOCAN estimates of incidence and mortality worldwide for 36 cancers in 185 countries. CA Cancer J Clin. 2018;68(6):394-424.

2. Huncharek M, Kupelnick B. In regards to Baujat et al.: Chemotherapy in locally advanced nasopharyngeal carcinoma: An individual patient data meta-analysis of eight randomized trials and 1753 patients (Int J Radiat Oncol Biol Phys 2006;64:47-56). Int J Rad Oncol Biol Phys. 2006;65(3):958 author reply 958-959.

3. Blanchard P, Lee A, Marguet S, Leclercq J, Ng WT, Ma J, Chan AT, Huang PY, Benhamou E, Zhu G, et al. Chemotherapy and radiotherapy in nasopharyngeal carcinoma: an update of the MAC-NPC meta-analysis. Lancet Oncol. 2015;16(6):645-55.

4. Chan AT, Gregoire V, Lefebvre JL, Licitra L, Hui EP, Leung SF, Felip E, Group E-E-EGW. Nasopharyngeal cancer: EHNS-ESMO-ESTRO Clinical Practice Guidelines for diagnosis, treatment and follow-up. Ann Oncol. 2012; 23(Suppl 7):vii83-5.

5. National Comprehensive Cancer Network. NCCN guidelines: head and neck cancers version 1. 2019.
6. Moher D, Liberati A, Tetzlaff J, Altman DG, Group P. Preferred reporting items for systematic reviews and meta-analyses: the PRISMA statement. Open Med. 2009;3(3):e123-30.

7. Jadad AR, Moore RA, Carroll D, Jenkinson C, Reynolds DJ, Gavaghan DJ, McQuay HJ. Assessing the quality of reports of randomized clinical trials: is blinding necessary? Control Clin Trials. 1996;17(1):1-12.

8. Fountzilas G, Ciuleanu E, Bobos M, Kalogera-Fountzila A, Eleftheraki AG, Karayannopoulou G, Zaramboukas T, Nikolaou A, Markou K, Resiga L, et al. Induction chemotherapy followed by concomitant radiotherapy and weekly cisplatin versus the same concomitant chemoradiotherapy in patients with nasopharyngeal carcinoma: a randomized phase II study conducted by the Hellenic Cooperative Oncology Group (HeCOG) with biomarker evaluation. Ann Oncol. 2012;23(2):427-35.

9. Tan T, Lim WT, Fong KW, Cheah SL, Soong YL, Ang MK, Ng QS, Tan D, Ong WS, Tan $\mathrm{SH}$, et al. Concurrent chemo-radiation with or without induction gemcitabine, carboplatin, and paclitaxel: a randomized, phase 2/3 trial in locally advanced nasopharyngeal carcinoma. Int J Rad Oncol Biol Phys. 2015;91(5):952-60.

10. Sun Y, Li W-F, Chen N-Y, Zhang N, Hu G-Q, Xie F-Y, Sun Y, Chen X-Z, Li J-G, Zhu $X-D$, et al. Induction chemotherapy plus concurrent chemoradiotherapy versus concurrent chemoradiotherapy alone in locoregionally advanced nasopharyngeal carcinoma: a phase 3 , multicentre, randomised controlled trial. Lancet Oncol. 2016;17(11):1509-20

11. Li W-F, Chen N-Y, Zhang N, Hu G-Q, Xie F-Y, Sun Y, Chen X-Z, Li J-G, Zhu X$D$, Hu C-S, et al. Concurrent chemoradiotherapy with/without induction chemotherapy in locoregionally advanced nasopharyngeal carcinoma: longterm results of phase 3 randomized controlled trial. Int I Cancer. 2019; 145(1):295-305.

12. Cao SM, Yang Q, Guo L, Mai HQ, Mo HY, Cao K, Qian CN, Zhao C, Xiang $Y Q$, Zhang XP, et al. Neoadjuvant chemotherapy followed by concurrent chemoradiotherapy versus concurrent chemoradiotherapy alone in locoregionally advanced nasopharyngeal carcinoma: A phase III multicentre randomised controlled trial. Eur J Cancer (Oxford, England : 1990). 2017;75: 14-23.

13. Yang Q, Cao S-M, Guo L, Hua Y-J, Huang P-Y, Zhang X-L, Lin M, You R, Zou $X$, Liu Y-P, et al. Induction chemotherapy followed by concurrent chemoradiotherapy versus concurrent chemoradiotherapy alone in locoregionally advanced nasopharyngeal carcinoma: long-term results of a phase III multicentre randomised controlled trial. Eur J Cancer (Oxford, England : 1990). 2019;119:87-96.

14. Frikha M, Auperin A, Tao Y, Elloumi F, Toumi N, Blanchard P, Lang P, Sun S, Racadot $\mathrm{S}$, Thariat J, et al. A randomized trial of induction docetaxelcisplatin-5FU followed by concomitant cisplatin-RT versus concomitant cisplatin-RT in nasopharyngeal carcinoma (GORTEC 2006-02). Ann Oncol. 2018;29(3):731-6.

15. Hong RL, Hsiao CF, Ting LL, Ko JY, Wang CW, Chang JTC, Lou PJ, Wang HM, Tsai MH, Lai SC, et al. Final results of a randomized phase III trial of induction chemotherapy followed by concurrent chemoradiotherapy versus concurrent chemoradiotherapy alone in patients with stage IVA and IVB nasopharyngeal carcinoma-Taiwan cooperative oncology group (TCOG) 1303 study. Ann Oncol. 2018;29(9):1972-9.

16. Zhang Y, Chen L, Hu G-Q, Zhang N, Zhu X-D, Yang K-Y, Jin F, Shi M, Chen Y-P, Hu W-H, et al. Gemcitabine and Cisplatin induction chemotherapy in nasopharyngeal carcinoma. N Engl J Med. 2019;381(12):1124-35.

17. Chen YP, Guo R, Liu N, Liu X, Mao YP, Tang LL, Zhou GQ, Lin AH, Sun Y, Ma J. Efficacy of the additional Neoadjuvant chemotherapy to concurrent Chemoradiotherapy for patients with Locoregionally advanced nasopharyngeal carcinoma: a Bayesian Network meta-analysis of randomized controlled trials. J Cancer. 2015;6(9):883-92.

18. Song $Y$, Wang $W$, Tao G, Zhou X. Survival benefit of induction chemotherapy in treatment for locally advanced nasopharyngeal carcinoma--a time-to-event meta-analysis. Oral Oncol. 2015;51(8):764-9.

19. OuYang PY, Zhang XM, Qiu XS, Liu ZQ, Lu L, Gao YH, Xie FY. A pairwise meta-analysis of induction chemotherapy in nasopharyngeal carcinoma. Oncologist. 2019;24(4):505-12.

20. Chen YP, Tang LL, Yang Q, Poh SS, Hui EP, Chan ATC, Ong WS, Tan T, Wee J, Li WF, et al. Induction chemotherapy plus concurrent Chemoradiotherapy in endemic nasopharyngeal carcinoma: individual patient data pooled analysis of four randomized trials. Clin Cancer Res. 2018;24(8):1824-33.

21. Tan TH, Soon YY, Cheo T, Ho F, Wong LC, Tey J, Tham IWK. Induction chemotherapy for locally advanced nasopharyngeal carcinoma treated with 
concurrent chemoradiation: a systematic review and meta-analysis. Radiother Oncol. 2018;129(1):10-7.

22. Mao YP, Xie FY, Liu LZ, Sun Y, Li L, Tang LL, Liao XB, Xu HY, Chen L, Lai SZ, et al. Re-evaluation of 6 th edition of AJCC staging system for nasopharyngeal carcinoma and proposed improvement based on magnetic resonance imaging. Int J Radiat Oncol Biol Phys. 2009;73(5):1326-34.

23. Lai SZ, Li WF, Chen L, Luo W, Chen YY, Liu LZ, Sun Y, Lin AH, Liu MZ, Ma J. How does intensity-modulated radiotherapy versus conventional twodimensional radiotherapy influence the treatment results in nasopharyngeal carcinoma patients? Int J Radiat Oncol Biol Phys. 2011;80(3):661-8.

24. Zhang MX, Li J, Shen GP, Zou X, Xu JJ, Jiang R, You R, Hua YJ, Sun Y, Ma J, et al. Intensity-modulated radiotherapy prolongs the survival of patients with nasopharyngeal carcinoma compared with conventional twodimensional radiotherapy: A 10-year experience with a large cohort and long follow-up. Eur J Cancer (Oxford, England : 1990). 2015;51(17):2587-95.

25. Chen L, Hu CS, Chen XZ, Hu GQ, Cheng ZB, Sun Y, Li WX, Chen YY, Xie FY, Liang SB, et al. Adjuvant chemotherapy in patients with locoregionally advanced nasopharyngeal carcinoma: Long-term results of a phase 3 multicentre randomised controlled trial. Eur J Cancer (Oxford, England : 1990). 2017;75:150-8.

26. Liu S-L, Sun X-S, Yan J-J, Chen Q-Y, Lin H-X, Wena Y-F, Guo S-S, Liu L-T, Xie $\mathrm{H}-J$, Tang Q-N, et al. Optimal cumulative cisplatin dose in nasopharyngeal carcinoma patients based on induction chemotherapy response. Radiother Oncol. 2019;137:83-94.

27. Xu C, Sun R, Tang L-L, Chen L, Li W-F, Mao Y-P, Zhou G-Q, Guo R, Lin A-H, Sun $Y$, et al. Role of sequential chemoradiotherapy in stage II and low-risk stage III-IV nasopharyngeal carcinoma in the era of intensity-modulated radiotherapy: a propensity score-matched analysis. Oral Oncol. 2018;78:3745.

28. Wang F, Jiang C, Sun Q, Ye Z, Liu T, Liu J, Sakamoto M, Wu P, Shi K, Qin W, et al. Addition of chemotherapy to intensity-modulated radiotherapy does not improve survival in stage II nasopharyngeal carcinoma patients. J Cancer. 2018:9(11):2030-7.

29. Mott FE, Ferrarotto R, Nguyen T, Phan J. Nasopharyngeal carcinoma outcome with induction chemotherapy followed by concurrent chemoradiotherapy. Oral Oncol. 2018:81:75-80

30. Liu T, Sun Q, Chen J, Li B, Qin W, Wang F, Ye Z, Hu F. Neoadjuvant chemotherapy with fluorouracil plus Nedaplatin or Cisplatin for locally advanced nasopharyngeal carcinoma: a retrospective study. J Cancer. 2018; 9(20):3676-82.

31. Liu G-Y, Lv X, Wu Y-S, Mao M-J, Ye Y-F, Yu Y-H, Liang H, Yang J, Ke L-R, Qiu $W$-Z, et al. Effect of induction chemotherapy with cisplatin, fluorouracil, with or without taxane on locoregionally advanced nasopharyngeal carcinoma: a retrospective, propensity score-matched analysis. Cancer Commun. 2018;38.

32. Li Y, Tang LQ, Liu LT, Guo SS, Liang YJ, Sun XS, Tang QN, Bei JX, Tan J, Chen $S$, et al. Induction chemotherapy plus concurrent chemoradiotherapy versus concurrent chemoradiotherapy alone in locoregionally advanced nasopharyngeal carcinoma in children and adolescents: a matched cohort analysis. Cancer Res Treat. 2018;50(4):1304-15.

33. Li P-J, Mo H-Y, Luo D-H, Hu W-H, Jin T. The efficacy of induction chemotherapy in the treatment of stage II nasopharyngeal carcinoma in intensity modulated radiotherapy era. Oral Oncol. 2018;85:95-100.

34. Zhang Q, Wang Y, Liao J-F, Ren Y-F, Shen G-P, Niu S-Q, Luo W. Long-term survival and prognostic factors in Locoregionally advanced nasopharyngeal carcinoma patients treated with TPF induction chemotherapy followed by Cisplatin-combined concurrent Chemoradiotherapy. J Cancer. 2019;10(17): 3899-907.

35. Yang $\mathrm{H}$, Chen X, Lin S, Rong J, Yang M, Wen Q, Shang C, He L, Ren P, Xu S, et al. Treatment outcomes after reduction of the target volume of intensitymodulated radiotherapy following induction chemotherapy in patients with locoregionally advanced nasopharyngeal carcinoma: a prospective, multicenter, randomized clinical trial. Radiother Oncol. 2018;126(1):37-42.

36. Toumi N, Ben Kridis W, Mnejja W, Bouzguenda R, Khanfir A, Ghorbel A, Daoud J, Frikha M. TPF induction chemotherapy followed by concurrent chemoradiotherapy for locally advanced nasopharyngeal carcinoma: long term results of a Tunisian series. Cancer Radiother. 2018;22(3):216-21.

37. Casanova M, Ozyar E, Patte C, Orbach D, Ferrari A, Veyrat-Follet C, Errihani H, Pan J, Zhang $L$, Shen $L$, et al. International randomized phase 2 study on the addition of docetaxel to the combination of cisplatin and 5 -fluorouracil in the induction treatment for nasopharyngeal carcinoma in children and adolescents. Cancer Chemother Pharmacol. 2016;77(2):289-98.
38. Fuwa N, Kodaira T, Daimon T, Yoshizaki T. The long-term outcomes of alternating chemoradiotherapy for locoregionally advanced nasopharyngeal carcinoma: a multiinstitutional phase II study. Cancer Med. 2015;4(8):118695.

39. Hui EP, Ma BB, Leung SF, King AD, Mo F, Kam MK, Yu BK, Chiu SK, Kwan $W H, H o$ R, et al. Randomized phase II trial of concurrent cisplatinradiotherapy with or without neoadjuvant docetaxel and cisplatin in advanced nasopharyngeal carcinoma. J Clin Oncol. 2009;27(2):242-9.

40. Zhang L, Huang Y, Hong S, Yang Y, Yu G, Jia J, Peng P, Wu X, Lin Q, Xi X, et al. Gemcitabine plus cisplatin versus fluorouracil plus cisplatin in recurrent or metastatic nasopharyngeal carcinoma: a multicentre, randomised, open-label, phase 3 trial. Lancet. 2016;388(10054):1883-92.

41. Zeng Z, Yan RN, Tu L, Wang YY, Chen PR, Luo F, Liu L. Assessment of concurrent Chemoradiotherapy plus induction chemotherapy in advanced nasopharyngeal carcinoma: Cisplatin, fluorouracil, and Docetaxel versus gemcitabine and Cisplatin. Sci Rep. 2018;8(1):15581.

\section{Publisher's Note}

Springer Nature remains neutral with regard to jurisdictional claims in published maps and institutional affiliations.

Ready to submit your research? Choose BMC and benefit from:

- fast, convenient online submission

- thorough peer review by experienced researchers in your field

- rapid publication on acceptance

- support for research data, including large and complex data types

- gold Open Access which fosters wider collaboration and increased citations

- maximum visibility for your research: over $100 \mathrm{M}$ website views per year

At BMC, research is always in progress.

Learn more biomedcentral.com/submissions 